\title{
Importance of coherence between geophysical and geotechnical data in dynamic response analysis
}

\author{
Mourad Karray $^{1,{ }^{*}, \text { Simon-Pierre Tremblay }}{ }^{1}$, Mahmoud N. Hussein ${ }^{1}$ and Mohamed Chekired ${ }^{2}$ \\ ${ }^{1}$ Université de Sherbrooke, Civil Engineering and Building Department, 2500 boulevard de l'Université, Canada \\ ${ }^{2}$ Institut de recherché d'Hydro-Québec, Varennes, Québec, Canada
}

\begin{abstract}
The demand for a precise evaluation of shear wave velocity $V_{s}$, is gaining interest in the field of geotechnical engineering due to its importance as a key parameter required to properly evaluate typical characteristics of soils. Nowadays, $V_{s}$ measurements are performed on the field using different methods, such as SCPT tests and various geophysical methods. However, the effectiveness of these field measurements is not guaranteed and rather depends on how they are analyzed. Furthermore, a proper analysis is critical since the collected data may be used in liquefaction evaluation or earthquake ground response analyses. In these situations, it is recommended to verify the coherence between the obtained geophysical $\left(V_{s}\right)$ and geotechnical $\left(N\right.$-SPT, $q_{c}$-CPT) measurements using alternative methods (e.g., $V_{s}$-correlations, $\mathrm{H} / \mathrm{V}$ method, etc...). In some situations, the correlation between the different measurements makes it easier to unambiguously define seismic wave profiles. In other cases, geophysical and geotechnical tests would provide different resolutions for $V_{s}$ measurements, an issue that complicates the decision of the practitioner. In this paper, we first demonstrate the importance of the shear-wave velocity in liquefaction potential analysis. A case study performed in eastern Canada is also presented where we show the importance of the method used to calculate $V_{s}$ profiles (MASW, MMASW).
\end{abstract}

\section{Introduction}

The disturbing effects of soil liquefaction have not sprung to the attention of researchers and geotechnical engineers until 1964 when two major earthquakes shook Anchorage, Alaska and Niigata, Japan. Both earthquakes produced spectacular examples of major damage to buildings, bridges, buried structures, highways, and utilities [1]. Liquefaction also caused severe damages in several seismic events such as in the Marina District in San Francisco during the 1989 Loma Prieta earthquake, in Kobe during the 1995 Great Hanshin earthquake, and in the Eastern part of Japan during the 2011 earthquake off the Pacific coast of Tohoku. While these cases serve as relatively recent examples, similar cases of sand liquefaction were reported much earlier [2].

\section{Methodology and methods}

First, the paper begins by shortly presenting the simplified methodology typically used to compute the liquefaction potential of soils in terms of the cyclic stress ratio (CSR). Second, numerical modelling is used to show some of the limitations of the simplified procedure to estimate the liquefaction potential in Eastern Canada. A particular emphasis is given on the importance to consider the regional seismicity and to define the correct soil dynamic properties to properly evaluate the liquefaction potential.
Third, a case study where SPT tests and $V_{s}$ measurements were performed using different methods is also described. Although the availability of the results obtained from different tests (SPT, CPT, Vs) may be beneficial, in several cases such as the one presented in this study, those tests lead to the calculation of different liquefaction potential. Deciding how much weight should be placed on a given approach/methodology is therefore not trivial [3].

In the case study, the $N$-SPT values are used to evaluate both the CSR and CRR of the soil. To evaluate the CSR, the $N$-SPT values are first converted to shearwave velocities $\left(V_{s}\right)$ and the CRR is evaluated using the procedure presented in [4].

The liquefaction potential calculated based on the SPT tests are then compared to those obtained with the Multichannel Analysis of Surface Waves (MASW) and the Multi Modal Analysis of Surface Waves (MMASW) methods in order to compare the effectiveness of both methods. The MMASW method was developed by the Civil Engineering department of the Université de Sherbrooke in the 1990s [5]. It was developed with the aim to meet the needs for accuracy and reliability required for engineering analyses in order to overcome the higher modes difficulties meet with the use of the method SASW (Spectral Analysis of Surface Wave) developed at the University of Texas in the 1980s [6]. Compared to other surface wave methods, the MMASW method is based on the identification and separation of all surface-wave

\footnotetext{
* Corresponding author: mourad.karray@usherbrooke.ca
} 
modes participating in the recorded traces. The latter offers several advantages such as an improved reliability and accuracy and it offers the possibility to calculate the correct Poisson ratio profiles $[5,7,8]$. With the MMASW method, surface waves are generated with a mechanical impact (a hammer of $63.5 \mathrm{~kg}$ dropped from a constant height of $2 \mathrm{~m}$ ) on the ground surface and the ground acceleration is recorded using accelerometers. The energy transmitted to the ground is sufficient to characterize soil deposits to a depth of at least $50 \mathrm{~m}$ [5]. It is important to distinguish the patented MMASW method developed to meet engineering needs from the MASW method, developed mainly for geophysical applications [9, 24].

\section{Liquefaction studies}

During the last 50 years, extensive liquefaction research has been carried out by hundreds of researchers around the world and a variety of methods for evaluating the liquefaction potential of soils have been proposed. The most common of these approaches, the cyclic stress approach, is based on a comparison of the earthquakeinduced cyclic shear stress ratio (i.e., the seismic demand of a soil layer, CSR) with the shear stress ratio required to cause liquefaction (i.e., the soil capacity to resist liquefaction, CRR) [e.g., 4, 10, 11]. Although it is conceptually quite simple, application of the stress approach requires careful attention to the manner in which CSR and CRR are characterized. The cyclic stress ratio, CSR can be predicted either by a detailed ground response analysis or by the simplified procedure suggested by [10] as:

$$
C S R=\frac{\tau_{a v}}{\sigma_{v 0}^{\prime}}=0.65\left(\frac{a_{\max }}{g}\right)\left(\frac{\sigma_{v}}{\sigma_{v 0}^{\prime}}\right) r_{d}
$$

where $\tau_{a v}$ is the average peak shear stress at the depth of interest; $\sigma_{v}$ and $\sigma^{\prime}{ }_{v 0}$ the corresponding total and effective vertical overburden stresses, respectively; $a_{\max }$ the peak ground surface acceleration; $g$ the acceleration of gravity and $r_{d}$ the stress reduction coefficient that accounts for the soil profile flexibility. Hence, the simplified procedure is performed without the need of detailed site response studies. However, recent studies have shown some of the limitations of the simplified procedure especially those linked to the evaluation of the stress reduction coefficient $[12,13,14]$. Our study also highlights the limitations of the simplified procedure linked to the use of a general $r_{d}$ coefficient. Moreover, we show the importance of considering the local seismicity and to have access to reliable field data in order to accurately evaluate the liquefaction potential in Eastern Canada.

The early work on the characterization of the cyclic resistance ratio of soil, CRR emphasized the use of laboratory cyclic testing. Subsequent studies showed that the liquefaction resistance of soil is influenced by factors other than the initial density and stress states such as soil fabric, OCR, and the prior seismic straining [e.g., 1, 15]. Indubitably, CRR can be evaluated based on laboratory cyclic tests on undisturbed soil specimens retrieved from the potentially liquefied site. However, retrieving undisturbed samples from the field is often a difficult task limiting the usefulness of the evaluation of the liquefaction potential based on laboratory testing. Field tests therefore remain essential for routine liquefaction investigations.

\subsection{Shear-wave velocity measurements}

In situ geotechnical (e.g., standard penetration test blow count, $\mathrm{N}$-SPT, and cone penetration resistance, $q c$-CPT) and geophysical methods (i.e. spectral analysis of surface waves (SASW), multichannel analysis of surface waves (MASW) and multi-modal analysis of surface waves (MMASW)) enabling the calculation of the shear-wave velocity $\left(V_{s}\right)$ are now commonly used for the evaluation of CRR. Unlike $N$-SPT and $q c$-CPT that can only be measured in the field, $V_{s}$ can be advantageously measured both in the field and in the laboratory under real and controlled conditions [16]. Moreover, $V_{s}$ measurements are possible in hard-to-penetrate deposits. In fact, $V_{s}$ appears to be preferred over $N$-SPT and $q c$-CPT in liquefaction potential analyses since it has the advantage of linking the cyclic liquefaction resistance CRR of the soil to its seismic demand CSR. Indeed, the ground seismic acceleration in Eq. 1 is associated with shear stress that is proportional to the shear strain as shown in equation 2 .

$$
\gamma=\tau / G=\frac{\tau}{G_{\max }\left(\frac{G}{G_{\max }}\right)}
$$

where $G$ and $G_{\max }$ are the soil shear modulus and initial shear modulus that is directly related to $V_{s}$. In other words, $V_{s}$ is directly related to both the seismic demand CSR and the liquefaction resistance CRR as it will be discussed next.

\subsection{Importance of local seismicity and site conditions}

Consider a $20 \mathrm{~m}$ sand deposit in Montreal (Canada) region with the CSR profile estimated from cyclic shear stresses induced at different levels in the deposit by a detailed analysis of the ground response to earthquakes using the computer code, FLAC [17]. The analysis was conducted using an elasto-plastic soil model (SIG4) compatible with the $G / G_{\max }$ limits established by [10] for sand. A synthetic earthquake record with a magnitude $\mathrm{M}=7.0$ compatible with the 2005 National Building Code of Canada (NBCC) spectrum (class A) as shown in Fig. 1, is used in the analysis [18]. Note that Eastern Canadian ground motions are generally richer in high-frequency energy and of shorter durations than Western Canadian or American earthquakes of the same magnitude.

In FLAC analysis, a homogenous deposit has been considered by adopting a constant value of normalized shear wave velocity $\left(V_{S I}\right)$ from which the shear modulus is then calculated using equation 3 :

$$
G=\rho V_{s}^{2}=\rho V_{s 1}^{2}\left(\frac{\sigma^{\prime} v}{100}\right)^{0.5}
$$




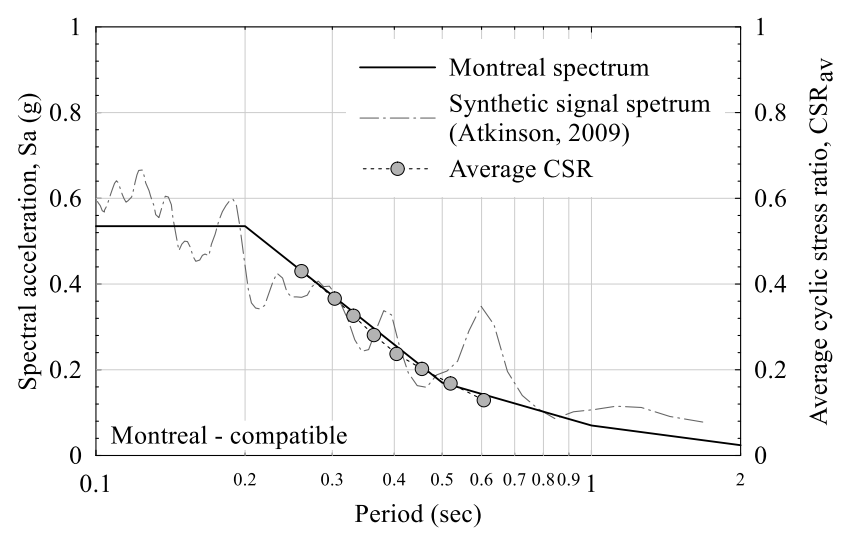

Fig. 1. Average CSR spectrums and the corresponding spectral accelerations $\mathrm{Sa}(\mathrm{g})$ for a seismic record compatible with Montreal.

where $\sigma^{\prime}{ }_{v}$ is the effective vertical stress, $\rho$ is the density, $P_{a}$ is atmospheric pressure in the same units as $\sigma^{\prime}$ (i.e., $P a$ $\approx 100 \mathrm{kPa}$ if $\sigma^{\prime}{ }_{v}$ is in $\mathrm{kPa}$ ). The variations of the computed $\operatorname{CSR}\left(0.65 \tau_{\max } / \sigma^{\prime}{ }_{v 0}\right)$ profiles with the adopted $V_{s l}$ are plotted in Fig. 2.

Figure 2 shows that the cyclic stress ratio increases with the increase of shear modulus (i.e., as the soil becomes stiffer and probably denser). This implies that there is a necessity to accurately measure $V_{s}$, and the current soil classification used in Canada is not refined enough for an accurate dynamic analysis.

For example, according to the NBCC, a given soil is classified as $\mathrm{D}$ if the average $V_{s 30}$ value varies between 180 and $360 \mathrm{~m} / \mathrm{s}$. However, the CSR value largely varies within these velocities. In fact, the increase of CSR with the increase of $V_{s I}$ is related to the change of the dynamic characteristic of the deposit (i.e., the increase in the fundamental frequency of the ground). The decrease in the fundamental period of the deposit $(T)$ would in turn lead to an increase in the shear force. To illustrate this, circles corresponding to the average cyclic stress ratio shown in Figure 2 are plotted in Figure 1. Each of the 8 circles shown in Figure 1 corresponds to the mean value calculated from the CSR profiles shown in Figure 2 and can be correlated to the spectral acceleration $(\mathrm{Sa}(T))$.

Likewise, Figure 3 shows the computed ranges of stress reduction coefficient $r_{d}$ calculated in FLAC with the compatible synthetic record compared to the average profile suggested by [10] and the magnitude-dependent profiles proposed by [19]. Figure 3 shows that the profiles suggested by these two approaches overestimate the stress reduction coefficient calculated with FLAC. In fact, these $r_{d}$ profiles were developed mainly based on Western USA deposits which are different from the Eastern Canadian deposits in terms of their seismological, geological and geotechnical characteristics.

More specifically, the application of Seed \& Idriss's and Idriss \& Boulanger's $r_{d}$ profiles to the ongoing geotechnical applications in Eastern regions of North America would lead to over-conservatism in seismic design as shown by [20].

As demonstrated by the above hypothetical example, there is a need to validate the $V_{s}$ profile implemented in dynamic analysis. The shear-wave velocity constitutes an engineering soil property that can be measured along with conventional geotechnical tests (e.g., SCPT during CPT test), with down-hole tests using the SPT hole or alternatively, by using surface wave methods (e.g., MASW; MMASW). However, these different methods may provide different resolutions for $V_{s}$ measurements, and it is a difficult task to verify that the obtained $V_{s}$ are correct and accurate due to the lack of reliable references for comparison.

$$
\text { Cyclic stress ratio, CSR }
$$

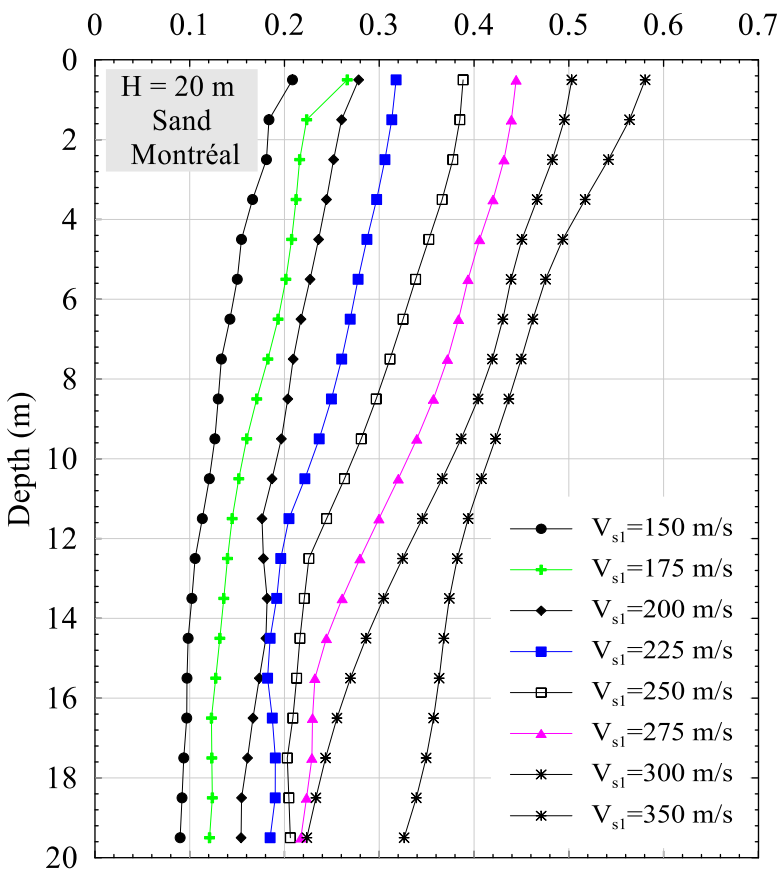

Fig. 2. Variation of the cyclic stress ratio CSR with the normalized shear wave velocity $V_{s l}$ for the synthetic record compatible with Montreal.

\section{Case study}

Direct measurement of $V_{s}$ on the field requires specialized equipment and technical expertise to ensure that the measured data are properly obtained and interpreted. In some cases, geophysical and geotechnical measurements may agree enabling an unambiguous decision process for the practitioners. In other cases however, geophysical and geotechnical tests would provide very different resolutions for $V_{s}$ measurements, an issue that complicates the decision for the practitioners.

In this paper, a case study where it was possible to perform different types of $V_{s}$ measurements is presented. The case study was performed on a soil deposit located near Québec city (Estimauville) in the province of Québec, Canada. First, SPT and MASW tests were performed to calculate the $N$-values and the $V_{s}$ profiles respectively (Figure 4).

Although several relationships exist to convert the measured $N$-values to $V_{s}$, the relationship proposed by [16] is used in this study since it was shown to be accurate in Eastern Canada:

$$
V_{s 1}=108 .\left(N_{1}\right)^{0.25} \cdot D_{50}^{0.18}
$$


Stress reduction coefficient, $r_{d}$

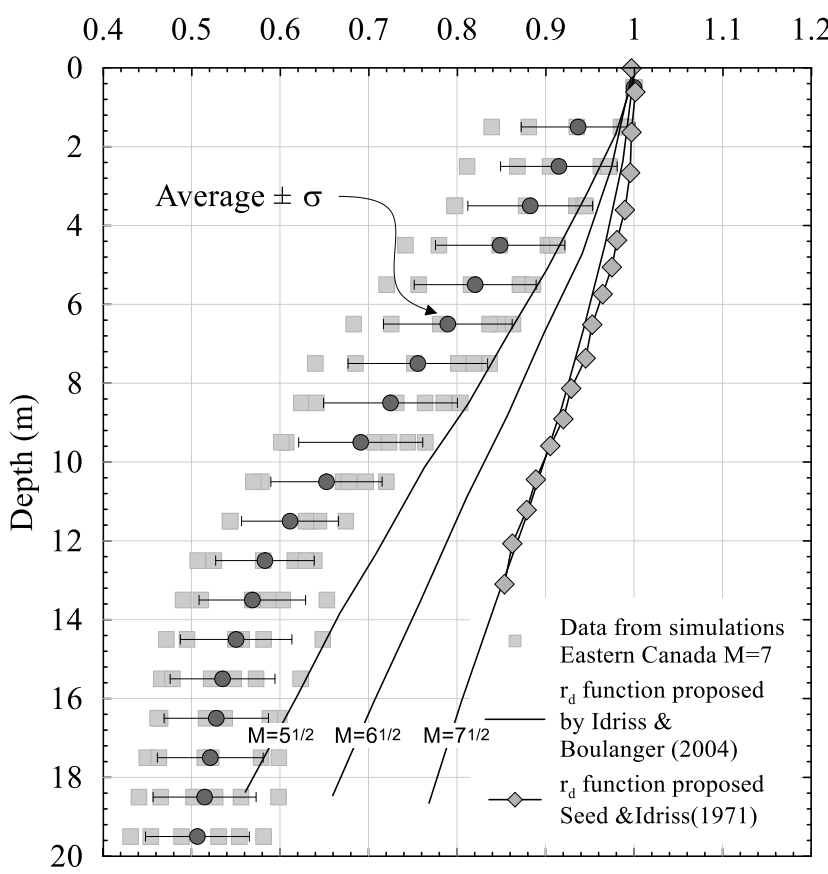

Fig. 3. Computed range of stress reduction factor compared to those proposed by [10] and [19] for a synthetic record compatible with the city of Montréal in Canada.

where $V_{s l}$ is the stress-normalized shear-wave velocity [4], $N_{l}$ is the standard penetration blow count corrected for the effective stress and $D_{50}$ is the mean grain size.

Within the depth where the $N$-values were obtained ( 0 $30 \mathrm{~m})$, Figure $4 \mathrm{~b}$ shows that the $V_{s}$ profiles calculated based on the $N$-values and the ones obtained with the MASW method do not agree. Indeed, the profiles obtained with the MASW method tend to have higher shear-wave velocities than those calculated base on the $\mathrm{N}$ values. Since no $N$-values were available below $30 \mathrm{~m}$, it was assumed that shortly below this depth, the $V_{s}$ profile would follow the one obtained with MASW. However, given the important difference between these two Vs profiles and their impact on the calculated CSR (Fig. 2), it was questionable whether this chose was reasonable and whether the correlation used to convert the $N$-values to $V_{s}$ was accurate.

Since the differences in the results obtained from both methods lead to different engineering design requirements, there was a need to conduct other tests to validate which results were accurate. Based on similar results obtained on other sites, it was necessary to perform another surface wave tests using the MMASW method.

The $V_{s}$ values obtained with the MMASW method are presented in Figure 5. As shown in Figure 5, two different MMASW test lines were performed. Figure 5 shows that the $V_{s}$ values determined with the MMASW method agree well with the $V_{s}$ profile calculated based on the $N$-values and that below $30 \mathrm{~m}$, there is no sudden increases of $V_{s}$ as assumed previously. The good correlation between the $V_{s}$ calculated with the MMASW method and from the $N$ values suggests that the $V_{s}$ calculated with the MASW method are not accurate.

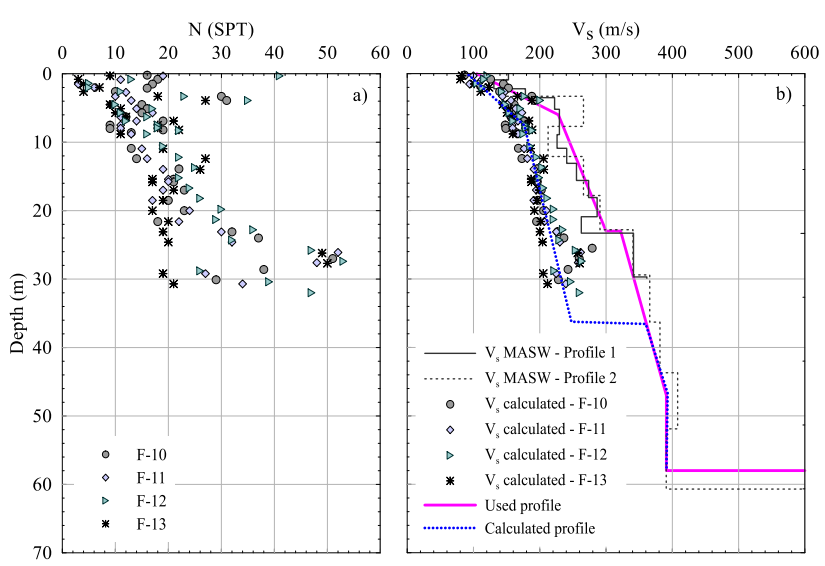

Fig. 4. (a) Measured $N$-values in four different boreholes. (b) Calculed $V_{s}$ profiles based on the $\mathrm{N}$-values and the MASW method. The full pink line and the dashed blue lines are the average $V_{s}$ profiles calculated using respectively the MASW and the $N$-values.

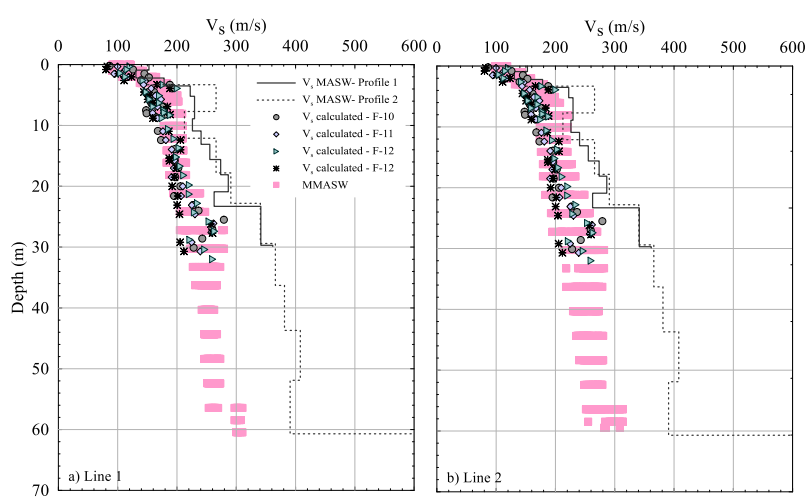

Fig. 5. Comparison between the different approaches used to calculate $V_{s}$ profiles.

The latter may happen due to the presence of higher Rayleigh-wave modes in the recorded traces that are not accounted for during the inversion. Indeed, higher modes may carry a significant amount of energy, sometimes event more than the R0 mode, event in normally dispersive soil deposits [21].

The computed cyclic stress ratio, CSR, calculated based on the $V_{s l}$ profile obtained using the MMASW and MASW methods and the $N$-SPT values (correlation) are compared to the estimated soil liquefaction resistance, CRR, calculated with the $N$ data following the procedure shown by [4] in Figure 6. The CSR are calculated with the procedure presented in section 3.2. Based on the MMASW profile, the whole deposit would be safe with an adequate margin of safety. Similarly, the $V_{s}$ profile calculated based on the $N$-SPT (labelled calculated profile in Figures 4 and 6) values indicates an adequate safety against liquefaction. The MASW results on the other hand indicate that the soil is susceptible to liquefaction at depths varying from 4 to $8 \mathrm{~m}$. In this situation, it is difficult for an engineer to decide whether the site should be judged safe or unsafe against liquefaction.

Microtremor measurements are often used to calculate the horizontal to vertical spectral ratio (HVSR). The HVSR can be used to validate the $V_{s}$ profiles calculated with other methods (MASW, MMASW, $N$-SPT) and therefore to help engineers decide which seismic-wave 
profile should be used for liquefaction potential analyses [22-23]. Figure 7 presents the spectral response, in terms of their transfer functions, of the same soil deposit but with their $V_{s}$ profiles calculated with the MASW method (Fig.4b) and with the MMASW method (Fig.5). The periods at which there are peaks in the spectral response presented in Figure 7 should correspond to peaks in the calculated HVSR. As shown in Figure 6, the higher values of $V_{s}$ found with the MASW method leads to a maximal spectral response located at lower periods (higher frequencies) than when the MMASW method was used. It can be observed that the average CSR values shown in Figure 6 correspond well to the CSR obtained from Figure 1 at the fundamental periods of $0.7 \mathrm{sec}$ and $0.9 \mathrm{sec}$ calculated using the MASW and MMASW profiles respectively. Considering the local seismicity of Eastern Canada, the latter is important since, as shown in Figure 1 , earthquakes happening in this region tend to be rich in lower period (higher frequency) waves. The spectral response determined based on the MASW $V_{s}$ profile is therefore more critical and would lead to incorrect engineering design considerations. Note that even if the MMASW $\mathrm{V}_{\mathrm{s}}$ profile correspond well to the one calculated using $N$-SPT, it would have been interesting to validate the spectral response of this soil deposit using $\mathrm{H} / \mathrm{V}$ measurements. However, no such recordings were performed on this site yet.
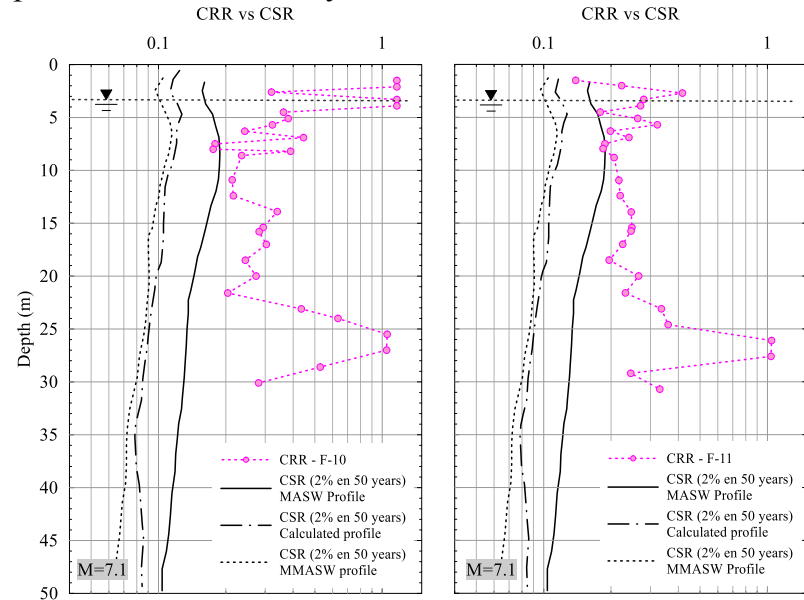

Fig. 6 Comparison between CSR calculated using 3 different $V_{s}$ profiles and CRR $(N$-SPT)

\section{Conclusions}

For many geotechnical problems such as liquefaction potential analysis, proper knowledge of the site condition and of the local seismic activity is of outmost importance to perform reliable dynamic analysis. Indeed, the consequences of a seismic event will vary depending on the local seismic activity and the local site conditions. The traditional cyclic stress approach may therefore fail to correctly evaluate the potential of liquefaction since it does not consider the effects of the local seismicity. Also, it was shown in this study that CSR is strongly affected by the $V_{s}$ profile adopted for dynamic analysis. However, identification of the site condition may also be problematic due to the diverging results obtained from different field tests ( $N$-SPT, down-hole, surface-wave methods). Field data used to perform dynamic analysis should therefore be used with caution and with the knowledge that they may not always be accurate.

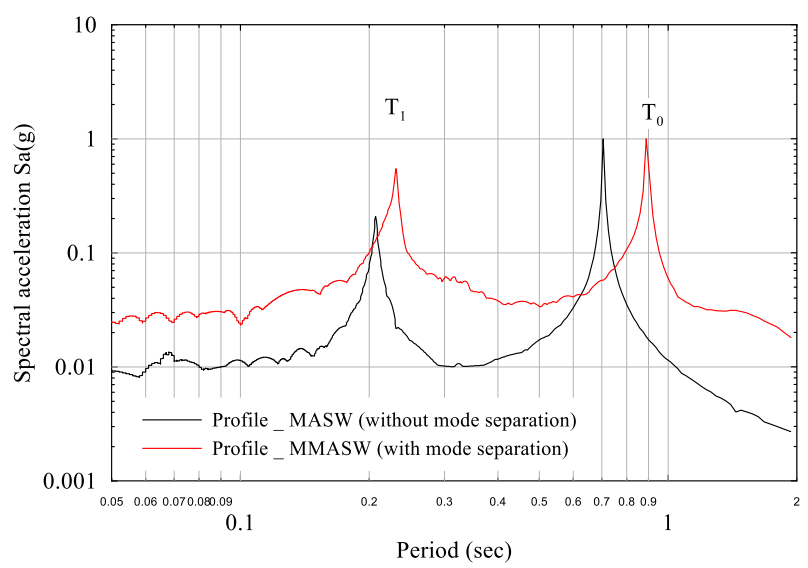

Fig. 7. Spectral responses, in terms of their transfer functions, calculated based on the $V_{s}$ profiles calculated with the MASW and MMASW methods for the same soil deposit. $T_{0}$ is the fundamental period and $T_{1}$ is the first higher period.

Finally, these conclusions imply that liquefaction potential analysis must be performed by considering the local seismic activity and with the use of reliable field test data. Given the importance of $V_{s}$ in liquefaction potential analysis, when possible, CPT $\left(V_{s}-q c\right)$ and SPT $\left(V_{s}-N\right)$ correlations as well as the $\mathrm{H} / \mathrm{V}$ spectral method can be used to verify the accuracy of $V_{s}$ calculated with geophysical methods.

\section{References}

1. Kramer, S.L. Geotechnical Earthquake Engineering (Prentice Hall, USA. 1996).

2. Hobbs, W.H. Earthquake. (D. Appleton Co., New York, N. Y. 1907)

3. Idriss, I. M., and Boulanger, R. W. Semi-empirical procedures for evaluating liquefaction potential during earthquakes. J. Soil Dynamics and Earthquake Eng., 26, 115-130 (2006).

4. Youd, T.L., et al. Liquefaction resistance of soils: summary report from the 1996 NCEER and 1998 NCEER/NSF workshops on evaluation of liquefaction resistance of soils. Journal of Geotechnical and GeoEnvironmental Engineering, 127(10), 817-33. (2001).

5. Karray, M. Utilisation de l'analyse modale des ondes de Rayleigh comme outil d'investigation géotechnique in-situ, Thèse de doctorat en génie civil, Département de génie, Université de Sherbrooke, Sherbrooke, (Québec), Canada. (1999)

6. Nazarian, S. In Situ Determination of Elastic Moduli of Soil Deposits and Pavement Systems by SpectralAnalysis-of Surface-Waves Method, Doctoral Dissertation, The University of Texas, Austin, Texas, 452 pages. (1984)

7. Lefebvre G., Karray. M. New Developments in in-situ Characterization Using Rayleigh Waves. 51 Canadian 
Geotechnical conference, Edmonton, Alberta, Canada. (1998)

8. Karray, M., G. Lefebvre. Significance and evaluation of Poisson's ratio in Rayleigh wave testing: Canadian Geotechnical Journal, 45(5): 624-635. (2008)

9. Park, C.B., Miller, R.D. and Xia, J. Multichannel analysis of surface waves (MASW); Geophysics, 64, p. 800-808. (1999)

10. Seed, H.B. and Idriss, I.M. Simplified procedure for evaluating soil liquefaction potential. Journal of the Soil Mechanics and Foundations Division, ASCE 97(9): 1249-1273. (1971)

11. Boulanger, R.W. \& Idriss, I.M. CPT and SPT Based Liquefaction Triggering Procedures. Dept. Civil \& Environmental Engineering, University of California at Davis, USA. (2014)

12. Cetin K.O. Reliability-based assessment of seismic soil liquefaction initiation hazard. Ph.D. Thesis, University of California at Berkeley, Berkeley, CA. (2000)

13. Lasley S, Green RA, Rodriguez-Marek A. A new stress reduction coefficient relationship for liquefaction triggering analyses. J Geotech Geoenviron Eng 142(11):06016013. (2016)

14. Green, R.A., Bommer, J.J., Rodriguez-Marek, A., Maurer, B.W., Stafford, P.J., Edwards, B., Kruiver, P.P., de Lange, G. \& van Elk, J. Addressing limitations in existing 'simplified' liquefaction triggering evaluation procedures: application to induced seismicity in the Groningen gas field, Bulletin of Earthquake Engineering (2018)

15. Finn, W. D., Bransby, P. L., and Pickering, D. J. Effect of strain history on liquefaction of sand: Am. Soc. Civil Engineers Proc., Jour. Soil Mechanics and Found. Div., 96(SM6) 1917-1934. (1970).

16. Hussien, M.N., and Karray, M. Shear wave velocity as a geotechnical parameter: an overview. Canadian Geotechnical Journal, 53(2): 252-272. (2016).

17. Itasca Consulting Group, FLAC. Fast lagrangian analysis of continua in 2-dimensions 6.0 (manual. Itasca, Minneapolis 2010).

18. Atkinson, G. M. Earthquake time histories compatible with the 2005 National building code of Canada uniform hazard spectrum. Canadian Journal of Civil Engineering, 36(6): 991-1000. (2009).

19. Idriss, I. M., and Boulanger, R. W. Semi-empirical procedures for evaluating liquefaction potential during earthquakes, in Proceedings 11th International Conference on Soil Dynamics and Earthquake Engineering, and 3rd International Conference on Earthquake Geotechnical Engineering, D. (2004).

20. Perret, D. Desgagnés, P. and Pelletier, S. A critical appraisal of some $r d$ relationships for liquefaction analyses in Eastern Canada with the simplified procedure. Proceedings, $66^{\text {th }}$ Canadian Geotechnical Conference, GeoMontreal, 8 p. (2013).
21. Karray, M., and Lefebvre, G. Techniques for mode separation in Rayleigh wave testing, Soil Dynamics and Earthquake Engineering, 29: 607-619. (2009).

22. Nakamura, Y., A method for dynamic characteristics estimation of subsurface using microtremor on the ground surface, QR RTRI, 30, 25-33. (1989).

23. Beroya, M. A. A., Aydin, A., Tiglao, R., and Lasala, M. Use of microtremor in liquefaction hazard mapping. Eng Geol 107:140-153. (2009).

24. Karray, M., Lefebvre, G. Patent: Method and Algorithm for Using Surface Waves. (U.S.A. 7,330,799)-(Canada. CA 2510016) (2003) 